\title{
Prevalence of Malnutrition in Patients at First Medical Oncology Visit in a Single Center Study
}

Dr. Happy ${ }^{1 *}$, Dr. Mahbub Emam Hossain², Dr. Nazir Uddin Mollah ${ }^{3}$, Dr. Mahir Mubir ${ }^{4}$, Dr. Muslah Uddin ${ }^{5}$, Dr. Tanjila Jahan $^{6}$

${ }^{1}$ Ex Head and Associate Professor, Department of Oncology, Holy Family Red Crescent Medical College and Hospital, Dhaka, Bangladesh

${ }^{2}$ Ex-Assistant professor, Department of Nuclear Medicine, National Institute of Kidney Diseases \& Urology, Dhaka, Bangladesh

${ }^{3}$ Associate Professor, Department of Oncology, Bangabandhu Sheikh Mujib Medical University, Dhaka, Bangladesh

${ }^{4}$ Medical Officer, Square Hospitals Ltd., Dhaka, Bangladesh

${ }^{5}$ Assistant register, Popular Medical College Hospital, Dhaka, Bangladesh

${ }^{6}$ Assistant register, Popular Medical College Hospital, Dhaka, Bangladesh

\author{
DOI: $10.36348 /$ sjmps.2022.v08i01.004 \\ | Received: 09.12.2021 | Accepted: 16.01.2022 | Published: 19.01.2022 \\ *Corresponding author: Dr. Happy \\ Ex Head and Associate Professor, Department of Oncology, Holy Family Red Crescent Medical College and Hospital, Dhaka, \\ Bangladesh
}

\section{Abstract}

Background: Malnutrition is associated to treatment toxicity, complications, reduced physical function, and lower survival in cancer patients. Malnutrition or associated risk was observed in the Prevalence of Malnutrition in Oncology (PreMiO) study among cancer patients visiting their first medical oncology appointment. Oncologists, not nutritionists, evaluated the nutrition status of the patients in this research, which was a first. Objective: The aim of the study was to evaluate the prevalence of malnutrition in patients at first medical oncology. Methods: PreMiO was a prospective, observational study conducted at Department of oncology, Bangabandhu Sheikh Mujib Medical University, Dhaka, Bangladesh. For inclusion, adult patients ( $>18$ years) had a solid tumor diagnosis, were treatment-naive, and had a life expectancy >3 months. Malnutrition was identified by the Mini Nutritional Assessment (MNA), appetite status with a visual analog scale (VAS), and appetite loss with a modified version of Anorexia-Cachexia Subscale (AC/S-12) of the Functional Assessment of Anorexia- Cachexia Therapy (FAACT). Results: Of patients enrolled $(N=50), 51 \%$ had nutritional impairment; $9 \%$ were overtly malnourished, and $43 \%$ were at risk for malnutrition. Severity of malnutrition was positively correlated with the stage of cancer. Over $40 \%$ of patients were experiencing anorexia, as reported in the VAS and FAACT questionnaire. During the prior six months, $64 \%$ of patients lost weight (1-10 kg). Conclusion: Even on their first visit to a medical oncology center, malnutrition, anorexia, and weight loss are prevalent in cancer patients.

Keywords: Malnutrition, anorexia, Oncology, nutritionists.

Copyright (C) 2022 The Author(s): This is an open-access article distributed under the terms of the Creative Commons Attribution 4.0 International License (CC BY-NC 4.0) which permits unrestricted use, distribution, and reproduction in any medium for non-commercial use provided the original author and source are credited.

\section{INTRODUCTION}

Most oncology units disregard the significant frequency of cancer-related malnutrition and its harmful repercussions. According to nutritional evaluations, malnutrition prevalence ranged from $25 \%$ to over $70 \%$ in studies from Germany [1], France [2-4], Spain [5], and Brazil [6]. Cancer patients are, in fact, among the malnourished of all patient groups [7]. When a precise assessment of body composition is employed for detection (e.g., computed tomography), malnutrition in cancer patients appears to be particularly visible; in such investigations, $50 \%$ to $80 \%$ of patients exhibited low lean body mass, a correlate of malnutrition [7]. However, many physicians, as well as patients and their companions, overlook the danger of malnutrition in cancer patients [2]. Malnutrition risk may not be appropriately handled even when it is detected. Only 1 in 3 cancer patients at risk of malnutrition in European got nutritional care, according to hospital studies [3, 5]. Untreated cancer-related malnutrition can have catastrophic effects. Colorectal cancer patients who were malnourished tolerated fewer chemotherapy cycles [9], but other cancer patients with sarcopenia/malnutrition were at high risk for 
Dr. Happy et al., Saudi J Med Pharm Sci, Jan, 2022; 8(1): 21-26

chemotherapy toxicity [10]. Moreover, malnourished oral cancer patients had lower quality of life (QOL) scores on physical function assessments, whereas those who were well-nourished and able to maintain or lose more weight had significantly improved QOL [11]. Malnutrition significantly raised the financial expenses of caring for cancer patients, such as longer hospital admissions and greater rates of complications after cancer-related surgery $[4,5,12]$. Malnourished patients had a 2- to 5-fold greater risk of dying than patients who showed little or no symptoms of malnutrition, according to both short- and long-term follow-up studies $[1,4,9]$.

Many oncologists ignore efforts for preventing and treating anorexia, cachexia, and sarcopenia due to a general lack of understanding of cancer-related malnutrition. The PreMiO research was designed to measure malnutrition and related symptoms in cancer patients who were seeing a medical oncologist for the first time in Bangladesh. Our ultimate objective is to improve oncologists' knowledge of the critical necessity for early nutritional assessment of cancer patients and provision of adequate nutritional therapy.

Melanoma malnutrition varies significantly from malnutrition caused by ordinary hunger [13]. Anorexia, cachexia (varying from pre-cachexia to cachexia), and sarcopenia (Figure 1) are some of the many causes and significant consequences of cancerrelated malnutrition [14, 15]. Malnutrition in cancer is caused by insufficient dietary intake, which can result in the depletion of body fat and lean mass, as well as impaired physical function [16]. Cancer patients may first notice appetite loss as a result of changed appetite cues [17]. Mouth ulcers, diarrhea, vomiting, discomfort, intestinal obstructions, or malabsorption are all examples of physical constraints that limit food intake and nutritional absorption in cancer patients [18, 19]. Pro-inflammatory cytokines generated by tumors or immune cells cause systemic inflammation, which is common in cancer [7]. This inflammation may raise the body's metabolic demands, suppress hunger, and cause muscle protein catabolism to speed. Cachexia, the consequent multifactor wasting illness, ranges from precachexia (defined by clinical symptoms and metabolic indicators) to refractory cachexia (characterized by substantial weight loss) $[7,10,14,15,20]$.

\section{Materials ANd Methods}

PreMIO was a prospective, observational, multicenter study to assess nutritional status and related factors in cancer patients PreMiO was a prospective, observational study conducted at Department of oncology, Bangabandhu Sheikh Mujib Medical University, Dhaka, Bangladesh. Inclusion criteria were: patients at first medical oncology visit; diagnosis of solid tumor; age $>18$ years; no previous anticancer therapies (e.g. radiotherapy or chemotherapy); life expectancy $>3$ months according to a palliative prognostic score [40]; and informed consent. Cancer type and stage of disease were determined by the oncologist. Exclusion criteria were inability to feed orally or intestinal obstruction; decompensated metabolic disorders; severe liver failure (total bilirubin $>1.5 \mathrm{mg} / \mathrm{dL}(25 \mu \mathrm{mol} / \mathrm{L})$, and aspartate aminotransferase (AST or SGOT) to alanine aminotransferase (ALT or SGPT) ratio >2-times the Upper Limit Normal (ULN) or, in the case of metastatic liver cancer, >5-times ULN; severe kidney failure indicated by creatinine $>2.0$ $\mathrm{mg} / \mathrm{dL}(177 \mu \mathrm{mol} / \mathrm{L})$ or creatinine clearance $(\mathrm{ClCr})$ $<50 \mathrm{~mL} / \mathrm{min}$; acute decompensated heart failure; active infection; primary brain tumor or metastatic brain tumors; severe psychiatric disorders; Mini-Mental State Examination (MMSE) score $<25 / 30$ (in patients aged >70). All statistical analyses were performed using IBM SPSS Statistics version 20.0 (SPSS Inc., Chicago, IL, USA).

\section{RESULTS}

Between Jnauary 2020 and June 2020, a total of 50 cancer patients ( 31 men and 19 women) were enrolled into the study on their first visit to a medical oncology center. Mean age (years) was 62.7 \pm 12.9 , mean BMI $(\mathrm{kg} / \mathrm{m} 2)$ was $24.8 \pm 4.4$, and mean weight $(\mathrm{kg})$ was $68.4 \pm 13.2$. With primary tumor stratification by site, breast cancer was the most frequent, followed by genitourinary tract, colorectal, and lung cancers (Table 1).

Table 1: Frequency of primary tumor types with distribution by tumor stage

\begin{tabular}{|l|l|l|l|l|l|}
\hline Primary tumor type & \% & Stage I \% & Stage II \% & Stage III \% & Stage IV \\
\hline Breast & 22.1 & 27.5 & 29.2 & 16.0 & 18.5 \\
\hline Genitourinary tract & 17.7 & 15.1 & 15.7 & 20.6 & 40.9 \\
\hline Colorectal & 16.3 & 4.1 & 11.0 & 29.2 & 50.9 \\
\hline Lung & 16.0 & 1.3 & 3.8 & 15.3 & 75.1 \\
\hline Other cancer & 7.2 & 17.0 & 6.4 & 10.6 & 41.8 \\
\hline Gastroesophageal & 6.5 & 7.1 & 4.8 & 15.9 & 64.3 \\
\hline Pancreatic & 4.8 & 0.0 & 4.3 & 18.3 & 67.7 \\
\hline Head and neck & 3.2 & 3.2 & 6.5 & 25.8 & 54.8 \\
\hline Other GI & 3.1 & 3.3 & 1.6 & 19.7 & 62.3 \\
\hline Liver/bile duct & 1.8 & 5.6 & 0.0 & 8.3 & 80.6 \\
\hline Unknown primary site & 1.3 & 0.0 & 0.0 & 4.0 & 56.0 \\
\hline Total & 100 & 11.6 & 12.9 & 18.7 & 48.0 \\
\hline
\end{tabular}




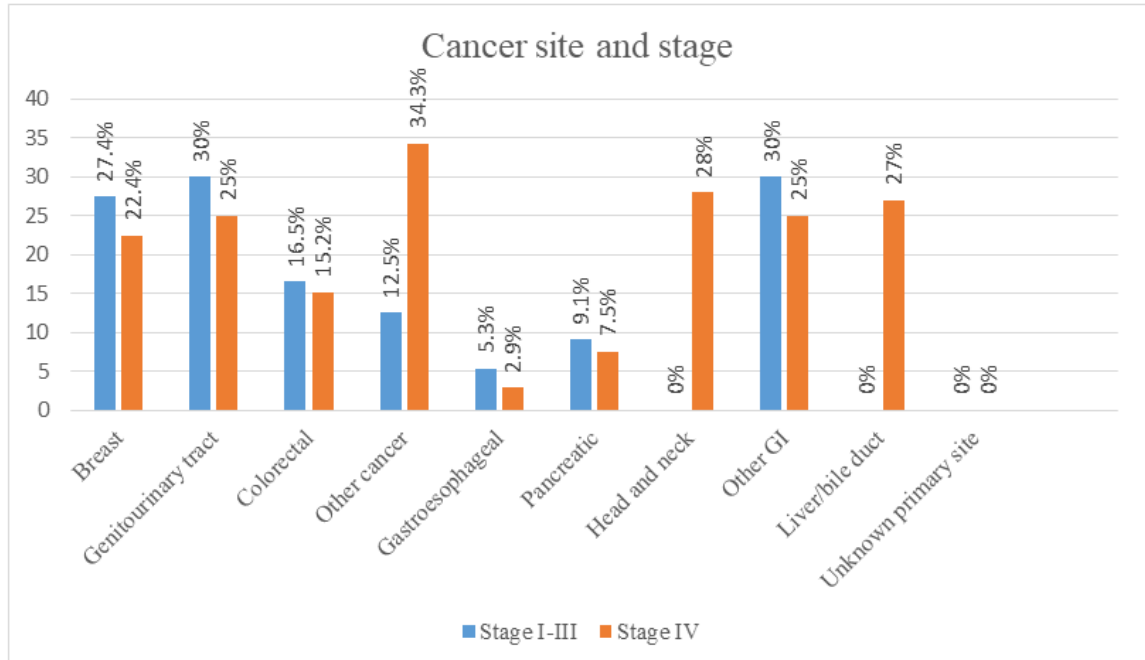

Figure I: Prevalence of pre-cachexia by cancer site, as determined by percent of patients

\section{DISCUSSION}

At Bagladeshi cancer care centers, oncology physicians enrolled patients in the PreMiO study and assessed nutritional status on their first visit for care. The oncologists reviewed recent weight changes, assessed appetite, looked for evidence of inflammation, and employed validated scoring methods and criteria to detect malnutrition, anorexia, and cachexia. Findings showed that first-visit PreMiO patients were often malnourished or at risk for malnutrition when they entered the study, i.e., $40 \%$ to $80 \%$ of patients had signs and indicators of nutritional impairment even in early disease stages, particularly in gastroesophageal, pancreatic, head and neck, and colorectal cancer patients. Importantly, our study demonstrated that oncologists can be effectively trained to perform assessments that identify malnutrition and its risks.

Malnutrition is prevalent with cancer, and both percent weight loss and BMI predict survival independently of conventional prognostic factors [26]. Accordingly, newly published expert guidelines advise nutrition screening and assessment for all cancer patients [18]. In the presence of a tumor, the body mounts an intense inflammatory response [27] associated with anorexia and cachexia, which can lead to progressive loss of skeletal muscle mass (with or without loss of fat mass) and worsen impairment of function [27]. The pathophysiology of cancer cachexia is characterized by negative protein and energy balance, which is driven by a variable combination of reduced food intake and abnormal metabolism [14]. Elevated blood CRP, a biochemical marker of inflammation, can be used to help detect cancer-related nutrition problems that predispose to poor outcomes [27]. Systemic inflammation was highly prevalent in PreMiO patients with non-metastatic disease, as well as for those with metastatic disease; based on CRP measures for $56 \%$ of study patients, inflammation by cancer site ranged from
$21 \%$ to $100 \%$ of M0 patients and $55 \%$ to $91 \%$ in M1 patients.

There is no simple biomarker for malnutrition nor is there expert agreement on which screening/ assessment tools are most accurate [28]. The MNA has been used successfully for lung cancer patients [29, 30], demonstrating a better predictive and prognostic value compared with measuring weight loss alone in the baseline nutritional evaluation of patients [30]. Because overweight and obesity are widespread today, malnutrition may be overlooked when conventional anthropometric measures such as height, weight, and body mass index are used exclusively for risk assessment [7]. It is therefore important to use screening tools and assessment methods that take other factors into account, e.g., recent weight loss, loss of appetite, loss of lean body mass, and impairment of physical abilities [29, 31, 32]. Specialized screening methods (bioimpedance analysis), and precise tools for assessment of lean body mass (computed tomography) are newly recognized as favorable ways to identify cancer-related malnutrition or its risk $[7,10,32]$. In this study, the prevalence of overt malnutrition (determined by MNA [33]) was considerably lower than the prevalence of cachexia (using Fearon's criteria [14]. This disparity is attributable largely to the different diagnostic criteria used to determine malnutrition and cachexia. Recently published guidelines from the European Society for Enteral and Parenteral Nutrition (ESPEN) [13], classify cachexia of chronic diseasesincluding cancer-as a form of "disease-related malnutrition (DRM) with inflammation," and propose that DRM with inflammation and cachexia are interchangeable terms. Nonetheless, while the concepts are aligned, the diagnostic criteria are different. This creates confusion that leads to delays in identifying and treating cancer-related malnutrition and cachexia in everyday clinical practice. We join with others to urgently call for scientific societies to align the definitions and diagnostic criteria of DRM with inflammation and cachexia [28]. 
Oncologists often question whether preventing or treating cancer-related malnutrition will affect their patients' prognosis. Recent evidence helps resolve the uncertainty, as available data suggest there are benefits of nutritional intervention to improve outcomes in cancer patients. For example, the high prevalence of malnutrition at diagnosis of gastric cancer was associated with high rates of surgical site infections following surgical tumor removal; the rate of surgical site infection was significantly reduced when patients were given well-managed pre-operative nutrition support [34]. Even for cancer patients who are not malnourished before surgery, 14-day pre-surgical nutrition therapy significantly improved nutritional status and reduced post-operative surgical complications compared to cancer patients who did not receive pre-surgical nutrition support [35]. When lung cancer patients were given high-energy oral nutritional supplements containing eicosapentaenoic acid (a fatty acid with inflammation-blunting properties), food intake and body composition improved, fatigue decreased, and appetite improved, as did measures of physical function and quality of life [36, 37].

Nutritional status affects acceptability and tolerability of anticancer therapies, in turn altering therapeutic choices. An accurate evaluation of nutritional status is of paramount importance in treating cancer patients, especially in early stages [32]. The efficacy of chemotherapy, for example, could be impaired by a reduction in the patient's therapy tolerance, which is influenced by a poor nutritional status [7, 38]. Lastly, in cancer patients, the relationship between disease curability/severity and subjective symptoms, such as appetite loss or degree of malnutrition, underlines the need for an integrated support team including a psycho-oncologist, who can address and treat psychological aspects (depression, loss of hope, and anxiety) while other team members deal with medical issues.

Altogether, results of the PreMiO study support a call-to-action for oncologists to (1) be aware of malnutrition risk in their patients, even in those with non-metastatic disease, (2) conduct early nutrition screening and make ongoing assessments of nutritional status of cancer patients, and (3) commit to early, aggressive treatment of malnutrition as part of routine supportive cancer treatments. We hope that as nutritional assessment and therapy become routine, survival and quality of life will improve for cancer patients [39].

\section{Limitation of the study}

The present study had some limitations. Larger number of population is needed for better evaluation.

\section{Conclusions}

Even on their first visit to a medical oncology center, malnutrition, anorexia, and weight loss are prevalent in cancer patients.

\section{ACKNOWLEDGEMENTS}

The wide range of disciplines involved in Malnutrition in Patients at First Medical Oncology Visit research means that an Editors needs much assistance from referees in the evaluation of papers submitted for publication. I am very grateful to many colleagues for their thorough, helpful and usually prompt response to requests for their opinion and advice.

\section{DeClaration \\ Funding: None funding sources.}

\section{Conflict of interest: None declared.}

Ethical approval: The study was approved by the informed consent of the participant patients

\section{REFERENCES}

1. Pressoir, M., Desné, S., Berchery, D., Rossignol, G., Poiree, B., Meslier, M., ... \& Bachmann, P. (2010). Prevalence, risk factors and clinical implications of malnutrition in French Comprehensive Cancer Centres. British journal of cancer, 102(6), 966-971.

2. Hébuterne, X., Lemarié, E., Michallet, M., de Montreuil, C. B., Schneider, S. M., \& Goldwasser, F. (2014). Prevalence of malnutrition and current use of nutrition support in patients with cancer.Journal of Parenteral and Enteral Nutrition, 38(2), 196-204.

3. Muscaritoli, M., Corsaro, E., \& Molfino, A. (2021). Awareness of cancer-related malnutrition and its management: analysis of the results from a survey conducted among medical oncologists. Frontiers in Oncology, 11.

4. Attar, A., Malka, D., Sabaté, J. M., Bonnetain, F., Lecomte, T., Aparicio, T., ... \& Taieb, J. (2012). Malnutrition is high and underestimated during chemotherapy in gastrointestinal cancer: an AGEO prospective cross-sectional multicenter study. Nutrition and cancer, 64(4), 535-542.

5. Planas, M., Álvarez-Hernández, J., León-Sanz, M., Celaya-Pérez, S., Araujo, K., \& De Lorenzo, A. G. (2016). Prevalence of hospital malnutrition in cancer patients: a sub-analysis of the PREDyCES $®$ study. Supportive Care in Cancer, 24(1), 429-435.

6. de Melo Silva, F. R., de Oliveira, M. G. O. A., Souza, A. S. R., Figueroa, J. N., \& Santos, C. S. (2015). Factors associated with malnutrition in hospitalized cancer patients: a croos-sectional study. Nutrition journal, 14(1), 1-8.

7. Ryan, A. M., Power, D. G., Daly, L., Cushen, S. J., Bhuachalla, Ē. N., \& Prado, C. M. (2016). Cancer- 
Dr. Happy et al., Saudi J Med Pharm Sci, Jan, 2022; 8(1): 21-26

associated malnutrition, cachexia and sarcopenia: the skeleton in the hospital closet 40 years later. Proceedings of the Nutrition Society, 75(2), 199-211.

8. Gyan, E., Raynard, B., Durand, J. P., Lacau Saint Guily, J., Gouy, S., Movschin, M. L., ... \& Savinelli, F. (2017). NutriCancer2012 Investigator Group. Malnutrition in patients with cancer. JPEN $J$ Parenter Enteral Nutr, 1, 148607116688881.

9. Aaldriks, A. A., van der Geest, L. G., Giltay, E. J., le Cessie, S., Portielje, J. E., Tanis, B. C., ... \& Maartense, E. (2013). Frailty and malnutrition predictive of mortality risk in older patients with advanced colorectal cancer receiving chemotherapy. Journal of geriatric oncology, 4(3), 218-226.

10. Prado, C. M., Cushen, S. J., Orsso, C. E., \& Ryan, A. M. (2016). Sarcopenia and cachexia in the era of obesity: clinical and nutritional impact. Proceedings of the Nutrition Society, 75(2), 188-198.

11. Gellrich, N. C., Handschel, J., Holtmann, H., \& Krüskemper, G. (2015). Oral cancer malnutrition impacts weight and quality of life. Nutrients, 7(4), 2145-2160.

12. Jean-Claude, M., Emmanuelle, P., Juliette, H., Michèle, B., Gérard, D., Eric, F., ... \& Gérard, N. (2012). Clinical and economic impact of malnutrition per se on the postoperative course of colorectal cancer patients. Clinical nutrition, 31(6), 896-902.

13. Cederholm, T., Barazzoni, R. O. C. C. O., Austin, P., Ballmer, P., Biolo, G. I. A. N. N. I., Bischoff, S. C., ... \& Singer, P. (2017). ESPEN guidelines on definitions and terminology of clinical nutrition. Clinical nutrition, 36(1), 49-64.

14. Fearon, K., Strasser, F., Anker, S. D., Bosaeus, I., Bruera, E., Fainsinger, R. L., ... \& Baracos, V. E. (2011). Definition and classification of cancer cachexia: an international consensus. The lancet oncology, 12(5), 489-495.

15. Muscaritoli, M., Anker, S. D., Argiles, J., Aversa, Z., Bauer, J. M., Biolo, G. I. A. N. N. I., ... \& Sieber, C. C. (2010). Consensus definition of sarcopenia, cachexia and pre-cachexia: joint document elaborated by Special Interest Groups (SIG)"cachexia-anorexia in chronic wasting diseases" and "nutrition in geriatrics". Clinical nutrition, 29(2), 154-159.

16. Lochs, H., Allison, S. P., Meier, R., Pirlich, M., Kondrup, J., Van den Berghe, G., \& Pichard, C. (2006). Introductory to the ESPEN guidelines on enteral nutrition: terminology, definitions and general topics. Clinical nutrition, 25(2), 180-186.

17. Blauwhoff-Buskermolen, S., Ruijgrok, C., Ostelo, R. W., de Vet, H. C., Verheul, H. M., de van der Schueren, M. A., \& Langius, J. A. (2016). The assessment of anorexia in patients with cancer: cutoff values for the FAACT-A/CS and the VAS for appetite. Supportive Care in Cancer, 24(2), 661666.

18. Arends, J., Bachmann, P., Baracos, V., Barthelemy, N., Bertz, H., Bozzetti, F., ... \& Preiser, J. C. (2017). ESPEN guidelines on nutrition in cancer patients. Clinical nutrition, 36(1), 11-48.

19. Farhangfar, A., Makarewicz, M., Ghosh, S., Jha, N., Scrimger, R., Gramlich, L., \& Baracos, V. (2014). Nutrition impact symptoms in a population cohort of head and neck cancer patients: multivariate regression analysis of symptoms on oral intake, weight loss and survival. Oral oncology, 50(9), 877-883.

20. Dev, R., Hui, D., Chisholm, G., Delgado-Guay, M., Dalal, S., Del Fabbro, E., \& Bruera, E. (2015). Hypermetabolism and symptom burden in advanced cancer patients evaluated in a cachexia clinic. Journal of cachexia, sarcopenia and muscle, 6(1), 95-98.

21. Martin, L., Birdsell, L., MacDonald, N., Reiman, T., Clandinin, M. T., McCargar, L. J., ... \& Baracos, V. E. (2013). Cancer cachexia in the age of obesity: skeletal muscle depletion is a powerful prognostic factor, independent of body mass index. Journal of clinical oncology, 31(12), 15391547.

22. Lieffers, J. R., Bathe, O. F., Fassbender, K., Winget, M., \& Baracos, V. E. (2012). Sarcopenia is associated with postoperative infection and delayed recovery from colorectal cancer resection surgery. British journal of cancer, 107(6), 931-936.

23. Prado, C. M., Lieffers, J. R., McCargar, L. J., Reiman, T., Sawyer, M. B., Martin, L., \& Baracos, V. E. (2008). Prevalence and clinical implications of sarcopenic obesity in patients with solid tumours of the respiratory and gastrointestinal tracts: a population-based study. The lancet oncology, 9(7), 629-635

24. Prado, C. M., Baracos, V. E., McCargar, L. J., Reiman, T., Mourtzakis, M., Tonkin, K., ... \& Sawyer, M. B. (2009). Sarcopenia as a determinant of chemotherapy toxicity and time to tumor progression in metastatic breast cancer patients receiving capecitabine treatment. Clinical cancer research, 15(8), 2920-2926.

25. Tan, B. H., Birdsell, L. A., Martin, L., Baracos, V. E., \& Fearon, K. C. (2009). Sarcopenia in an overweight or obese patient is an adverse prognostic factor in pancreatic cancer. Clinical cancer research, 15(22), 6973-6979.

26. Martin, L., Senesse, P., Gioulbasanis, I., Antoun, S., Bozzetti, F., Deans, C., ... \& Baracos, V. E. (2015). Diagnostic criteria for the classification of cancer-associated weight loss. Journal of Clinical Oncology, 33(1), 90-99.

27. Laviano, A., Koverech, A., \& Mari, A. (2015). Cachexia: clinical features when inflammation drives malnutrition. Proceedings of the Nutrition Society, 74(4), 348-354. 
Dr. Happy et al., Saudi J Med Pharm Sci, Jan, 2022; 8(1): 21-26

28. Argilés, J. M., \& Muscaritoli, M. (2017). Unifying diagnostic criteria for cachexia: An urgent need. Clinical Nutrition, 36(3), 910-911.

29. Gioulbasanis, I., Georgoulias, P., Vlachostergios, P. J., Baracos, V., Ghosh, S., Giannousi, Z., ... \& Georgoulias, V. (2011). Mini Nutritional Assessment (MNA) and biochemical markers of cachexia in metastatic lung cancer patients: interrelations and associations with prognosis. Lung cancer, 74(3), 516-520.

30. Gioulbasanis, I., Baracos, V. E., Giannousi, Z., Xyrafas, A., Martin, L., Georgoulias, V., \& Mavroudis, D. (2011). Baseline nutritional evaluation in metastatic lung cancer patients: Mini Nutritional Assessment versus weight loss history. Annals of oncology, 22(4), 835-841.

31. Isenring, E., \& Elia, M. (2015). Which screening method is appropriate for older cancer patients at risk for malnutrition?. Nutrition, 31(4), 594-597.

32. Muscaritoli, M., Molfino, A., Lucia, S., \& Fanelli, F. R. (2015). Cachexia: a preventable comorbidity of cancer. A TARGET approach. Critical reviews in oncology/hematology, 94(2), 251-259.

33. Guigoz, Y., Lauque, S., \& Vellas, B. J. (2002). Identifying the elderly at risk for malnutrition: The Mini Nutritional Assessment. Clinics in geriatric medicine, 18(4), 737-757.

34. Fukuda, Y., Yamamoto, K., Hirao, M., Nishikawa, K., Maeda, S., Haraguchi, N., ... \& Tsujinaka, T. (2015). Prevalence of malnutrition among gastric cancer patients undergoing gastrectomy and optimal preoperative nutritional support for preventing surgical site infections. Annals of surgical oncology, 22(3), 778-785.
35. Kabata, P., Jastrzębski, T., Kąkol, M., Król, K., Bobowicz, M., Kosowska, A., \& Jaśkiewicz, J. (2015). Preoperative nutritional support in cancer patients with no clinical signs of malnutritionprospective randomized controlled trial. Supportive Care in Cancer, 23(2), 365-370.

36. Sánchez-Lara, K., Turcott, J. G., JuárezHernández, E., Nuñez-Valencia, C., Villanueva, G., Guevara, P., ... \& Arrieta, O. (2014). Effects of an oral nutritional supplement containing eicosapentaenoic acid on nutritional and clinical outcomes in patients with advanced non-small cell lung cancer: randomised trial. Clinical nutrition, 33(6), 1017-1023.

37. Van der Meij, B. S., Langius, J. A., Spreeuwenberg, M. D., Slootmaker, S. M., Paul, M. A., Smit, E. F., \& van Leeuwen, P. A. (2012). Oral nutritional supplements containing $n-3$ polyunsaturated fatty acids affect quality of life and functional status in lung cancer patients during multimodality treatment: an RCT. European journal of clinical nutrition, 66(3), 399-404.

38. Muscaritoli, M., Molfino, A., Gioia, G., Laviano, A., \& Fanelli, F. R. (2011). The "parallel pathway": a novel nutritional and metabolic approach to cancer patients. Internal and emergency medicine, 6(2), 105-112.

39. Gangadharan, A., Choi, S. E., Hassan, A., Ayoub, N. M., Durante, G., Balwani, S., ... \& Suh, K. S. (2017). Protein calorie malnutrition, nutritional intervention and personalized cancer care. Oncotarget, 8(14), 24009-24030. 